\title{
Histological Appearance of Distal Second Part of Duodenum with Normal Endoscopic Findings in Bangladeshi People in a Tertiary Care Hospital
}

\author{
MOHAMMAD ENAMUL KARI M, ${ }^{1}$ MOHAMMAD MAHMUDUL HUDA, ${ }^{2}$ HASAN MASUD, ${ }^{3}$ PRODI P KUMAR BI SWAS, ${ }^{4}$ \\ MUSHTAQUE AHMED RANA, ${ }^{5}$ SUVASH CHANDRA VHADURY, ${ }^{6}$ MOHAMMAD AHSANUL HAQUE, ${ }^{7}$ DEWAN SAI FUDDIN \\ $\mathrm{AHMED}^{8}$
}

\begin{abstract}
:
Biopsy from the distal second part of duodenum is now widely accepted as a useful and simple way to evaluate patients with malabsorption or other small intestinal diseases. Histological findings of the second part of duodenumin tropical countries are different from that of other countries. Histological appearance of the second part of the duodenum may be changed due toceliac disease, tropical sprue, tropical enteropathy and some other conditions. As Bangladeshi people, we are exposed to different infection always due to its geographical distribution. Normal histological appearance of second part of duodenume.g. standard villous architecture, length, villous crypt ratio, IELcounts of our country in not known. The main objective of our study was to see the normal histological appearance of second part of duodenum in our country so that we can differentiate from abnormal condition.

This observational study was carried out in the Department of Gastroenterology \& Pathology, Bangabandhu Sheikh Mujib Medical University, (BSMMU)during the period of July 2010 to June 201 I. A total of I I 6 patients were included from out patientdepartment and admitted patient in the department of Gastroenterology during the study period. Among the total numbers, the mean age was $32.7 \pm 9.77$ ( \pm SD) years.In our study, $48.27 \%$ subjects had finger shaped villous with normal height, $27.58 \%$ had both normal and broad villous, $22.41 \%$ subjects showed mixed findings of normal, broad and blunted villous and only $1.7 \%$ subjects showed broad and blunted villous without normal architecture. In our study, the highest IEL count was 62 cells per 100 epithelial cells and lowest value was 16 . Mean value IEL/ I 00 cells were $32.52 \pm 8.63$ ( \pm SD) and $95 \% \mathrm{Cl}$ was I.57. The result of the study was very similar to Asian people but a little different from the western population.
\end{abstract}

Key words: Duodenum, endoscopy, histoloty

\section{Introduction:}

Small intestinal mucosa has typical histological pattern to meet the demand of digestion and absorption of the nutrients. Different diseases cause mucosal distortions of the normal villous pattern impairing digestion and absorption. ${ }^{1}$ Distal

1. Assistant Professor, Department of Gastroenterology, Shaheed Suhrawardy Medical College, Dhaka.

2. Assistant Professor, Department of Pathology, Dhaka National Medical College, Dhaka.

3. Professor, Department of Gastroenterology, Bangabandhu Sheikh Mujib Medical University, (BSMMU), Dhaka.

4. Resident (Gastroenterology), BSMMU, OSD, DGHS, Mohakhali, Dhaka.

5. Assistant Professor, Department of Gastroenterology, Dhaka National Medical College, Dhaka.

6. Assistant Professor, Department of Medicine, Sheikh Sayera Khatun Medical College, Gopalganj.

7. Assistant Professor, Department of Medicine, Comilla Medical College, Comilla.

8. Professor, Department of Gastroenterology, BSMMU, Dhaka. Correspondence : Dr. Mohammad Enamul Karim, MBBS, FCPS, MD. Assistant Professor, Department of Gastroenterology, Shaheed Suhrawardy Medical College,Dhaka. Mob: 01819116464, e-mail:meknasim@gmail.com. part of second part of duodenum (D2) represents the same histological structure of the entire small intestine. As a result biopsy from D2 is now widely accepted as a useful and simple way to evaluate patients with primary intestinal malabsorption or other intestinal diseases. ${ }^{2}$ The epithelial component of the small bowel is composed of villi and crypts (crypts of Liberkuhn). Normal villous to crypt length ratio is approximately 3:1 to 5:1. When four normal villi are identified in a specimen, it usually indicates that the entire specimen has a normal villous architecture except focal lesion. ${ }^{3}$ The villi are normally ridge or leaf shaped in the human proximal duodenum, leaf or finger shaped in the distal duodenum and proximal jejunum, and finger shaped in the distal jejunum and ileum.Intestinal intraepithelial lymphocytes (IELs) are unique T cell population interspersed between epithelial cells of both the small and large intestine. They have been proposed to have a wide variety of immunological roles, particularly in response to antigen(s) in the gut lumen. ${ }^{4}$ It is becoming increasingly recognized that high numbers of Intraepithelial lymphocytes (IELs) with normal villous architecture is within the wide spectrum of histological abnormalities observed in Gluten Sensitivity 
(GS). ${ }^{4,6,7,8,9}$ Therefore, it is important to recognize this finding in small bowel biopsy samples. Moreover, there are many clinicopathological features with some descriptions of tropicalenteropathy with increased villous intraepithelial lymphocytes. ${ }^{10}$

An endoscopically normal-appearing mucosa may have histopathological changes. ${ }^{11}$ Thus, the evaluation of a routine duodenal biopsy specimen is a valuable diagnostic aid in recognizing unsuspected pathology in dyspeptic patients or those with atypical gastrointestinal symptoms. ${ }^{12}$

\section{Materials and methods}

Type of study:

It was an observational, cross sectional study which was carried out in the department of Gastroenterology and Pathology, Bangabandhu Sheikh Mujib Medical University, (BSMMU), Dhaka, Bangladesh from July 2010 to June 2011. A total number of 116 patients attending the Gastroenterology OPD of BSMMU with dyspeptic symptoms and those dyspeptic patients admitted in the Gastroenterology ward and who were found to be normal at upper GITendoscopy were selected for the study.

\section{Sampling:}

Non-probability sampling.

\section{Inclusion criteria:}

(a)Patients having dyspeptic symptoms with normal endoscopic findings. (b)Age of 18-60 years (c)Ambulatory patients of both sexes (d)Patients willing to undergo upper GI endoscopy and biopsy.

\section{Exclusion criteria:}

(a) Patients with contraindications to upper GI endoscopy(b) Patients who had erosion, ulcer or malignancy in the stomach or duodenum (c) Patients who had abnormal looking mucosa in the second part of duodenum(d) Patientsof PUD and its complications like active bleeding and pyloric stenosis (e) Known patient of malabsorption, motility disorder, malignancy or previous gastric surgery (c) Known patient of allergy to certain food like, gluten, cereals, cow's milk, soy products, fish, rice and chicken. (d) Patients who were on NSAIDs, alcohol. (e) Patients who were pregnant (f) Unwilling for endoscopy.

\section{Ethical consideration:}

After proper explanation written informed written consent was obtained from the selected patients for upper GI endoscopy and biopsy. Study design was approved by the ethical committee of BSMMU.

\section{Data processing:}

Data were collected using standard data collection sheet. Histological findings of duodenal biopsy specimen according to study design were complied. All the data obtained from the study were analyzed using SPSS version 14 .

\section{Results:}

Total 116 individuals were included for the study. Among the total numbers, the mean age was $32.7 \pm 9.77( \pm S D)$ years.

Out of 116 subjects, 84 (72.41\%) were male and 32 (27.5\%) were female. Ratio of the male and female was 2.6: 1.Table-I shows the sex distribution of the patients.

Table-I

Sex distribution of the subjects

\begin{tabular}{lccccccc}
\hline Sex & $\begin{array}{c}<1 \\
\text { Years }\end{array}$ & $\begin{array}{c}21-30 \\
\text { years }\end{array}$ & $\begin{array}{c}31-40 \\
\text { years }\end{array}$ & $\begin{array}{c}41-5 \\
\text { years }\end{array}$ & $\begin{array}{c}51-60 \\
\text { years }\end{array}$ & $\begin{array}{c}>60 \\
\text { years }\end{array}$ & $\begin{array}{c}\text { Total } \\
\text { No. }\end{array}$ \\
\hline Male & 4 & 40 & 27 & 9 & 2 & 2 & 84 \\
Female & 3 & 10 & 10 & 7 & 2 & 0 & 32 \\
\hline
\end{tabular}

Among the total number of patients, 38.79\% came from rural area and $61.20 \%$ came from urban area.

In our study, the normal looking mucosa showed the variable histological appearance. The following table shows the variation of villous height and architecture.

Table II

Villous height and architecture:

\begin{tabular}{lcc}
\hline Histological structure & Frequency Percentage \\
\hline $\begin{array}{l}\text { Finger shaped villous with normal } \\
\text { height }\end{array}$ & 56 & $48.27 \%$ \\
Normal and broad villous & 32 & $27.58 \%$ \\
Normal, broad and blunted villous & 26 & $22.41 \%$ \\
$\begin{array}{l}\text { Broad and blunted villous without } \\
\text { normal shape }\end{array}$ & 2 & $1.7 \%$ \\
\hline
\end{tabular}

Among the total number, 96 cases showed normal appearance crypt structure and 20 slides showed hyperplasia of crypts. None of the selected patients had alteration of villous to crypt ratio. Surface enterocytes showed no abnormality in any patient.

The highest intraepithelial lymphocytes (IEL) count was 62 cells per 100 epithelial cells (EC) and lowest value was 16 . Mean value IEL/100 cells was $32.52 \pm 8.63$ ( \pm SD) and 95\%CI was 1.57.Pattern of intraepithelial lymphocytes per 100 cells among the 116 patients showed in the table III. 
Table III

Intra epithelial lymphocyte / 100 eipthelial cells

\begin{tabular}{lcc}
\hline IEL /100 EC & Frequency & Percentage \\
\hline$<20$ & 4 & $3.44 \%$ \\
$20-39$ & 89 & $76.72 \%$ \\
$40-59$ & 22 & $18.96 \%$ \\
$60+$ & 1 & $0.8 \%$ \\
\hline
\end{tabular}

The lamina propria showed large number of lymphocytes in 76 (65.51\%) individuals, moderate number of lymphocytes in 35 (30.17\%) individuals and mild lymphocyte infiltration in only 5 (4.31\%) subjects. Good number of patients showed plasma cell and some patients showed eosinophil in the lamina propria. Only 8 (6.89\%) patients showed dilatation of lamina propria.

None patient's histology showed any organism in the epithelium. No evidence of metaplasia was detected. No evidence of neoplasm was detected.

\section{Discussion:}

Biopsy from the distal second part of duodenum is now widely accepted as a useful and simple way to evaluate patients with malabsorption or other small intestinal diseases. ${ }^{2}$ To diagnose certain intestinal disease, normal histological appearance will guide us to differentiate abnormal pathology. ${ }^{13}$ There are several studies about normal histological appearance of second part of duodenum in the different part of the world. Maximum study described villous architecture and normal level of IEL. Normal histological appearance of second part of duodenumeg.standard villous architecture, length of the villous, villous crypt ratio, IEL count of our country in not known. Some diseases are very common in tropical countries like tropical sprue, tropical enteropathy. People of our country are always facing infective agents eg. virus, bacteria, H.pylori, protozoa which are recognized cause of changes of normal histological appearance. $^{14}$

In our study, $48.27 \%$ subjects had finger shaped villous with normal height, $27.58 \%$ had both normal and broad villous, $22.41 \%$ subjects showed mixed findings of normal, broad and blunted villous and only $1.7 \%$ subjects showed broad and blunted villous without normal architecture. Rubin CE et al., Segal GH et al , Mino M et al ${ }^{3,15,16}$ showed that villous morphology may be related to geographical areas: in temperate areas villi were longer, with a finger-like appearance, whereas in tropical areas leaf-like and ridge-like variants are present in the proximal duodenum and the fingerlike variants occur distally. Our findings are comparable to the result of Rubin CE et al, Segal GH et al, Mino M et al study. We found $82.75 \%$ to have normal appearance of crypt, $17.24 \%$ to have hyperplasia and there was no villous to crypt ratio alteration in visual assumption.

In this study, the highest intraepithelial lymphocytes count were 62 cells per 100 epithelium cells (EC) and lowest value was 16/100 EC. Mean value IEL/100 cells was $32.52 \pm 8.63$ ( \pm SD) and 95\%CI was 1.57. Nasseri.S et al (2008) found upper limit of IEL 34/100 EC in H \& E and 35 IEL/ 100 EC in Immunohistochemical (IHC) study in endoscopically normal second part of duodenum in Iran. IEL level in Iranian people is very close to our observation. ${ }^{17}$ In Australia, Ian Brown et al (2006) described more than 25/100 EC IEL in H \& E in normal villous architecture of second part of duodenum. This study showed lower number of IEL in comparison to our study. ${ }^{14}$ Veress et al ( 2004) at Sweden described the upper limit of IEL was 25/100 EC in H \& E in endoscopically normal second part of duodenum. This study showed very similar result to Ian Brown et al. ( 2006) but lower count of IEL in comparison to our study. ${ }^{14,18}$ Sanjay Kakar et al ( 2003) described the upper limit of IEL was 40/100 EC in H \& E in endoscopically normal second part of duodenum. This result looks very similar to our study. ${ }^{19}$

Biagi F et al. (2003), in Italy found the upper limit of IEL was 4.6/100 EC in H \& E in endoscopically normal second part of duodenum. This study shows disparity in comparison to our study. ${ }^{20}$ Mahadeva et al (2002) in UK showed the upper limit of Intraepithelial lymphocyte count was 22/100 EC in H \& E in endoscopically normal second part of duodenum. This study showed lower number IEL in respect to our study. ${ }^{21}$ Goldstein et al (2001) showed the upper limit of Intraepithelial lymphocyte count was 24/100 EC in H \& E in endoscopically normal second part of duodenum. This study also had lower value of IEL than our study. ${ }^{9}$ In all studies except Nasseri. S et al (2008) and Kakar et al (2003) showed disparity about IEL count in comparison to our study. Considering the IEL count per 100 epithelial cells, our study is nearly similar to the developing country and different from the developed country. The result of IEL count of our study shows very close result to Indian, Iranian and Indonesian people but different from the study conducted in Europe, USA, UK and Australia.

\section{Conclusion:}

Biopsy from the distal second part of duodenum is a useful and simple way to evaluate patients with malabsorption or other small intestinal diseases. ${ }^{2}$ The histological appearance of the second part of duodenum is variable in different part of the world. Histological appearance of normal endoscopic findings in our study is very close to Asian people but different from Western and other part of the world. Villous 
architecture was variable. We found a good number of people had broad and blunted villous. Mean value IEL/100 cells was more than study of UK, Italy, USA, Australia but closely similar to study in Iran, India and Indonesia. The reasons of variation of villous architecture and IEL were not evaluated. May be, Bangladesh is a tropical country like India, Iran and Indonesia. The people are always exposed to various infectious agents. But actual cause is not known. To validate this further prospective multi-centre trial is required.

\section{Limitations of the study}

There are several limitations of this study:

Firstly, the sample size was too small and study period was short.

Secondly, to know the normal histological appearance of the second part of duodenum in Bangladeshi people, a population based study should be done in the community. The exact normal histological appearance of this study is not the reflection of the country. Moreover, the study was conducted with dyspeptic patient. Healthy individual's normal histology will give more rational result.

Thirdly, asymptomatic celiac disease was not excluded for the study.

Fourthly, villous height and crypt length were not measured and IEL count was done only by $\mathrm{H}$ \& E, no immunohistochemical study was done to count the lymphocytes.

\section{Conflict of Interest : None}

\section{References:}

1. Lawrence R, Schiller. Malabsorption disorder.In:Current Diagnosis \& Treatment in Gastroenterology, 2nd edn. McGraw-Hill, 2003; 23: 368-88.

2. Serra S, Jani PA. An approach to duodenal biopsies. J Clin Pathol 2006; 59: 1133-1150.

3. Segal GH, Petras RE. Small intestine. In: Histology for pathologists. 2nd edn. Sternberg SS, eds. Philadelphia: Lippincott-Raven 1997:495-518.

4. FergusonA. Intraepithelial lymphocytes. Gut 1977; 18: 921-37.

5. Marsh MN, Crowe PT. Morphology of the mucosal lesion in gluten sensitivity. Baillieres Clin Gastroenterol 1995; 9: 273-93.

6. Ferguson A. Coeliac disease research and clinical practice: Maintaining momentum into the twenty-first century. Baillieres Clin Gastroenterol 1995; 9: 395412.

7. Picarelli A, Maiuri L, Mazzilli MC, et al. Gluten-sensitive disease with mild enteropathy. Gastroenterology 1996;111: 608-16.
8. Kaukinen K, Maki M, Partanen J, et al. Celiac disease without villous atrophy: Revision of criteria called for. Dig Dis Sci 2000; 46: 879-87.

9. Goldstein NS, Underhill J. Morphologic features suggestive of gluten sensitivity in architecturally normal duodenal biopsy specimens. Am J Clin Pathol 2001; 116: 63-71.

10. Veitch AM, Kelly P, Zulu IS, Segal I, Farthing MJ. Tropical enteropathy: a T-cell-mediated crypt hyperplastic enteropathy. Eur. J. Gastroenterol. Hepatol. 2001; 13: 1175-1181.

11. Kori M, Gladish V, Ziv-Sokolovskaya N, Huszar M, BeerGabel M, Reifen R. The significance of routine biopsies in pediatric patients undergoing upper intestinal endoscopy. J ClinGastroenterol 2003; 37: 39-41.

12. Hopper AD, Cross SS, Hurlstone DP, McAlindon ME, Lobo AJ, Hadjivassiliou M, et al. Symptomatic giardiasis without diarrhea: further evidence to support the routine duodenal biopsy? GastrointestEndosc 2003; 58:120-2.

13. Zhou H, Schaefer N, Wolff M, et al. Carcinoma of the ampulla of Vater: comparative histologic/immunohistochemical classification and follow-up. Am J SurgPathol 2004; 28: 875-82.

14. Brown I, Mino-Kenudson M, Deshpande V, LawersGY. Intraepithelial lymphocytosis in architecturally preserved proximal small intestinal mucosa: an increasing diagnostic problem with a wide differential diagnosis. Arch Pathol Lab Med 2006; 130: 1020-5.

15. Mino M, LauwersGY. Role of lymphocytic immunophenotyping in the diagnosis of gluten-sensitive enteropathy with preserved villous architecture. Am J Surg Pathol 2003; 27: 1237-42.

16. Lee SK, Lo W, Memeo L, et al. Duodenal histology in patients with celiac disease after treatment with a gluten-free diet. Gastrointest Endosc 2003; 57: 187-91.

17. SiavoshNasseri-Moghaddam, AzadehMofid, Mehdi Nouraie , BehnooshAbedi , AkramPourshams, Reza Malekzadeh et al. The Normal Range of Duodenal Intraepithelial Lymphocytes. Arch Iranian Med 2008; 11 (2): 136 - 142.

18. Veress B, Franzen L, Bodin L, et al. Duodenal intraepithelial lymphocytecount revisited. Scand J Gastroenterol 2004; 39 : 138-44.

19. Cellier C, Patey N, Mauvieux L, et al. Abnormal intestinal intraepithelial lymphocytes in refractory sprue. Gastroenterology 1998; 114: 471-81.

20. Zeitz M, Ullrich R, Schneider T, et al. HIV/SIVenteropathy. Ann N Y AcadSci 1998; 859: 139-48.

21. Mahadeva S, Wyatt JI, Howdle PD. Is a raised intraepithelial lymphocyte count with normal duodenal villous architecture clinically relevant? J Clin Pathol 2002; 55: 424-8. 